\title{
Understanding jobs-housing imbalance in urban China: A case study of Shanghai
}

\author{
Weiye Xiao \\ University of Utah \\ weiye.xiao@utah.edu \\ Han Li \\ University of Miami \\ han.li@miami.edu
}

\author{
Yehua Dennis Wei (corresponding author) \\ University of Utah and \\ Zhejiang University \\ wei@geog.utah.edu
}

\begin{abstract}
Shanghai has experienced a rapid process of urbanization and urban expansion, which increases travel costs and limits job accessibility for the economically disadvantaged population. This paper investigates the jobs-housing imbalance problem in Shanghai at the subdistrict-level (census-level) and reaches the following conclusions. First, the jobshousing imbalance shows a ring pattern and is evident mainly in the suburban areas and periphery of the Shanghai metropolitan area because job opportunities are highly concentrated while residential areas are sprawling. Second, structural factors such as high housing prices and sprawling development significantly contribute to the jobs-housing imbalance. Third, regional planning policies such as development zones contribute to jobs-housing imbalance due to the specialized industrial structure and limited availability of housing. However, geographically weighted regression reveals the development zones in the traditional Pudong district are exceptional insofar as government policy has created spatial heterogeneity there. In addition, the multilevel model used in this study suggests regions with jobs-housing imbalance usually have well-connected streets, and this represents the local government's efforts to reduce excessive commuting times created by jobs-housing imbalance.
\end{abstract}

Keywords: Urbanization; jobs-housing imbalance; spatial mismatch index; spatial inequality; Shanghai, China

\section{Introduction}

Jobs-housing balance is an urban planning tradition of matching the workplaces and residences. A jobs-housing balanced community is a self-contained one where people can both work and live (Giuliano, 1991). Thus, jobs-housing balance can refer to the distribution of employment relative to the distribution of workers within a given geographic area. Technically, urban scholars are using the spatial mismatch between employment and population to capture jobs-housing imbalance since the population census can roughly represent the distribution of residence. (e.g., Fan, Allen, \& Sun, 2014; Wang, Song, \& Xu, 2011).

Copyright 2021 Weiye Xiao, Yehua Dennis Wei \& Han Li

http://dx.doi.org/10.5198/jtlu.2021.1805

ISSN: 1938-7849 | Licensed under the Creative Commons Attribution - Noncommercial License 4.0

The Journal of Transport and Land Use is the official journal of the World Society for Transport and Land Use (WSTLUR) and is published and sponsored by the University of Minnesota Center for Transportation Studies.

\section{Article history:}

Received: May 19, 2020

8, 2020

Accepted: November 1, 2020

Available online: March 15,

2021 
Now jobs-housing imbalance has become a critical urban issue all over the world, particularly in large metropolises, causing increased distances and durations of commuting, rising income inequality, traffic congestion, air pollution, and decreasing upward mobility (Cervero \& Day, 2008; Ewing, Hamidi, Grace, \& Wei, 2016; Gobillon, Selod, \& Zenou, 2007; Pan, Sheng, \& Zhang, 2009; Yang \& Ferreira, 2005). However, the patterns, determinants, and victims of jobs-housing imbalance vary across urban contexts. In the United States, exclusionary zoning and high housing costs lead to undersupply of housing which contributes to jobs-housing imbalance (Cervero, 1989). In China, people living in peripheral areas suffer more from the jobs-housing imbalance because of highly centralized job opportunities (Wang \& Chai, 2009; Wang, Song, \& Xu, 2011). Thus, although the jobs-housing imbalance undermines urban sustainability and social resilience in both Chinese and US cities, its detailed dynamics and impacts need further study.

Thanks to massive public resources and employment opportunities, Shanghai has attracted millions of low-income migrants, regarded as the "floating population" (Li et al., 2019a; Olds \& Yeung, 2004; Yue, Fan, Wei, \& Qi, 2014). Given that people with similar socioeconomic status are likely to live in the same zone ( $\mathrm{Li}, 2010)$, these low-income migrants are generally concentrated in the fringe areas of Shanghai (Li et al., 2019b; You, Yang \& Fu, 2018). At the same time, public services are still concentrated in central districts, making them scarce goods for suburban residents. Aside from demographic suburbanization, fueled by the establishment of development zones, Shanghai has also experienced dramatic urban land expansion and spatial restructuring (Li, Lin, $\mathrm{Li}, \& \mathrm{Wu}, 2014)$, leading to a sophisticated urban structure with highly concentrated job centers (Cartier, 2001; Feng, Zuo, \& Ruan, 2002).

Rapid urban expansion and residential segregation have contributed to the jobs-housing imbalance in Shanghai, while the average commuting distance increased from 4.3 kilometers in 1986 to 6.8 kilometers in 2004 (SCCTPI, 2005). Recently, Sun, Ermagun, and Dan (2017) conducted a travel survey in Shanghai, and the results show that the commuting distance has reached 8.8 kilometers, and the average commuting time is about 40 minutes. This is the outcome of relocation towards suburban areas, which leads to poor job accessibility and long commuting times (Cervero \& Day, 2008). On the other hand, the housing prices are exceptionally high in Shanghai, which also causes a longer commuting time for the poor and middle classes. Moreover, the decentralization of job opportunities has failed in Shanghai. As the urban land keeps increasing, the spatial mismatch between employment and residence increases and the commuting distance/time would increase as well. Thus, the jobs-housing imbalance has become an important obstacle to build a sustainable Shanghai, and understanding its dynamics is the key to mitigating the problem in urban planning.

Jobs-housing imbalance in the United States is largely associated with social inequality indicators. (Gobillon et al., 2007; Ihlanfeldt, \& Sjoquist, 1998; Kain, 1992). Scholars have found that African Americans and Latinos, who are concentrated in the urban centers, have poorer access to quality jobs compared to whites. However, Shanghai is homogeneous ethnically (Han Chinese), and racial and ethnic differences apparently fail to explain the city's jobs-housing imbalance. The floating population, which includes both peasants and well-educated workers, mainly constitutes the socially disadvantaged population in urban China, and it is also is the most affected group by jobs-housing imbalance (Liang $\& \mathrm{Ma}, 2004)$. Moreover, in China, the monocentric urban structure plays a vital role in creating the jobs-housing imbalance problem (Liu, Fang, \& Li, 2014). This urban structure associated with the administrative hierarchy of the centralized Chinese state, especially the state-led development zones, is an essential determinant of the uneven spatial distribution of population and jobs (Han, Yang, Wang, Song, \& Zhang, 2015; Li, 2010). The unique urban demography and monocentric urban structure further escalate China’s jobs-housing imbalance.

This study explores the causes of jobs-housing imbalance with Chinese characteristics and seeks to 
answer the following questions. What are the spatial patterns of jobs-housing imbalance in Shanghai? How is the jobs-housing imbalance associated with the urban structure and regional planning policies? Does such a relationship vary across space? To answer these questions, first, we calculate a spatial mismatch index based on datasets of population and job opportunities to quantify the jobs-housing imbalance for each subdistrict in Shanghai. Second, we compare the spatial associations between distributions of population, job opportunities, and urban amenities using a jobs-housing imbalance index. Last, we explore the underlying determinants and their spatial heterogeneity with multilevel modeling and geographically weighted regression.

\section{$2 \quad$ Literature review}

A balanced jobs-housing relationship would be found where people live, work, shop, and recreate in a self-contained, self-reliant community (Cervero, 1989). Giuliano and Small (1993) argue that jobshousing balance could be defined as the distribution of employment relative to the distribution of workers within a given geographic area. With the development of urban areas, a trend of increasing commuting duration and jobs-housing imbalance can be observed. Due to economic agglomeration effects and the relocation of residences and job centers, the jobs-housing imbalance is becoming severe. Agglomeration economies concentrate job opportunities in the attempt to maximize the economic benefits; as a result, commuting increases (Qin \& Wang, 2017). Suburbanization leads to the relocation of job opportunities and residences; people who require inexpensive housing are often disconnected from their workplaces (Gobillon et al., 2007; Kain, 1992).

\subsection{Jobs-housing imbalance and determinants}

Studies of the determinants of jobs-housing imbalance can be divided into two groups (Horner \& Murray, 2003). One group focuses on the demographic and socioeconomic characteristics of workers, such as income, age, sex, race, educational attainment, and the self-selection (Cervero, 1989; Kim, Sang, Chun, \& Lee, 2012). Since people today are highly mobile thanks to the rapid development of transportation, the dynamic jobs-housing balance with proper commuting distance also could be accepted according to personal characteristics (Peng, 1997). Another perspective of jobs-housing imbalance is the spatial dimension since the spatial separation between the labor market and the housing market based on urban fabric necessitates commuting behavior (Suzuki \& Lee, 2012; Zhou, Chun, Xiaojian, Wei, \& Peng, 2014).

From the perspective of neoclassical economics, the jobs-housing imbalance is a co-location problem between residences and job centers (Anas, Arnott, \& Small, 1998). Thus, people's socioeconomic status and housing affordability play an essential role in a free housing market. The early research on spatial mismatch suggests that disadvantages in socioeconomic status and poor housing affordability limit the accessibility of job opportunities (Kain, 1992). Cervero (1989) found that a disparity between people's household income and housing prices is a driving force of jobs-housing imbalance. Thus, housing affordability can reflect people's socioeconomic status, and this has already become a key concern in explaining jobs-housing imbalance and commuting behavior (Suzuki \& Lee, 2012).

Urban geographers are interested in explaining jobs-housing imbalance based on changes in the urban structure such as decentralization of urban population and the relocation of job opportunities (Glaeser, Kahn, \& Rappapo, 2008; Stoll, 2005). The effects of urban structure on jobs-housing imbalance vary between monocentric cities and polycentric cities. In some monocentric cities, suburbanization of population and workplaces is found to reduce the commuting distance and time because people 
would change their residences or workplaces, or both, to adapt to worsening congestion and to maintain an acceptable commute distance and time (Giuliano \& Small, 1993; Gordon \& Richardson, 1989; Gordon \& Richardson, 1997; Saadi, Boussauw, Teller, \& Cools, 2016). However, in Bangkok, Thailand, the jobs-housing imbalance is created by workplaces suburbanizing while the population remains centralized for public amenities such as schools in the urban center (Lobyaem, 2006).

On the other hand, the theoretical model of polycentric cities implies a jobs-housing balance because people would choose residences close to the job subcenters (Gordon \& Richardson, 1989). The results of Loo and Chow's study (2011) support this hypothesis by comparing the impacts of different urban structures on jobs-housing balance. However, a study of polycentric metropolitan areas in France shows that people live in the sub-centers and work outside their residence (Aguilera, 2005). In this scenario, the polycentric urban structure contributes to jobs-housing imbalance and increases commuting time. Thus, there is not a consensus about the linkage between urban structure and jobs-housing imbalance. A case-by-case analysis considering local urban context including geographic, economic, and institutional factors, is needed (Ma \& Banister, 2007).

Furthermore, compared to western cities, government policies in Asian countries play an important role in shaping the urban structure and creating a jobs-housing imbalance. For example, the greenbelt policy in South Korea was reinforced by a strong government strategy to build very large new towns beyond the greenbelt, which results into a significant jobs-housing imbalance because people decentralized much faster than jobs (Bae \& Jun, 2003). Chinese global cities such as Beijing and Shanghai are still highly concentrated, however the national strategies such as developing new towns and development zones in suburban areas affect the spatial distribution of the job opportunities (Fan et al., 2014; Wang et al., 2011; Xu, Chan, \& Yung, 2013).

\subsection{Jobs-housing imbalance and the Chinese context}

In China, urban land expansion keeps pace with the urbanization of the population, and both population and job opportunities are decentralizing more rapidly than in western countries (He, Huang, \& Wang, 2014). Therefore, the jobs-housing imbalance is growing much faster than in western countries (Wang et al., 2011; Zhou et al., 2014). Current literature identifies the impacts of jobs-housing imbalance on people's daily lives and has uncovered several vital forces behind jobs-housing imbalance, such as the social inequality and urban structure (Cervero, 1989; Fan, et al., 2014; Horner \& Murray, 2003; Loo \& Chow, 2011; Wang \& Chai, 2009).

Social and income inequality in China is primarily influenced by the household registration system, which classifies people into the floating population and registered population. Migrants are usually recorded as the floating population who are typically disadvantaged in socioeconomic status. A significant jobs-housing imbalance is detected among blue-collar workers without hukou in Beijing (Wang et al., 2011). A study by Xu et al. (2013) explores the mechanism of jobs-housing imbalance in Shanghai and finds that socially disadvantaged people appear to live far away from employment centers because of a lack of affordable housing in Shanghai's core areas. On the other hand, a study in Guangzhou examines the influence of people's occupational status, finding that old and poor employees need to spend more time commuting than others (Zhou, Liu, \& Kwan, 2016). Thus, unlike the studies from Western countries that focus on racial differentiation and low-income population, studies on the jobs-housing imbalance in China should pay particular attention to poor migrant workers.

Furthermore, poor housing affordability is a primary barrier for poor people to live close to their workplaces (Kain, 1992). Housing was not a problem in the Maoist period because the employees lived in houses provided by Danwei (working unit), which are close to their workplaces (Wang \& Chai, 2009). Since the market-oriented reform began, the provision of housing has shifted from Danwei to 
the real estate market (Fan, et al., 2014; Wang \& Murie, 1996). Due to the fact that land revenue has become a leading revenue source for urban municipal governments, most Chinese metropolises such as Shanghai, Beijing, and Hangzhou have witnessed skyrocketing increases in housing prices (Li \& Huang, 2006; Sun, Zheng, Geltner, \& Wang, 2017). Therefore, people's housing affordability is decreasing, especially for the economically-disadvantaged floating population who usually live in the urban peripheries (Li, 2010; Li \& Wu, 2006). Although some poor migrating workers can live in urban villages (Bai, Shi, \& Liu, 2014), space in urban villages is limited, and it is not a sustainable solution because urban villages are likely to be replaced, given rapid urban development (Li et al., 2014).

The traditional urban theory suggests that the high house prices in the urban center would be compensated by reduced commuting costs. However, in China, there is little evidence suggesting that accessibility to job opportunities is a critical determinant of housing prices. Some recent studies demonstrate that skyrocketing home prices in China are largely contributed by the scarcity and monopoly of public services, such as public hospitals, school districts, and other amenities (Li et al., 2019a; Wen \& Goodman, 2013; Wen, Xiao, \& Zhang, 2017). In the central urban area where job opportunities are highly concentrated, is also the cluster of public services, which causes that the areas residential land is a scarce resource with extremely high prices. Thus, central districts with higher housing prices might also indicate a higher mismatch between employment and population, and low commuting costs are not expected to compensate for the extremely high housing prices.

As regards to urban structure, Chinese cities are highly concentrated; Liu and Wang (2016) find that about ninety percent of Chinese cities have fewer than four urban centers. In particular, the population in urban China is highly concentrated in the city cores (Liu, Dijst, \& Geertman, 2014; Wang et al., 2011). Some Chinese cities have started the transformation from a monocentric urban structure to a polycentric urban structure, and population and job opportunities are decentralizing (He, Zeng, Xie, Tan, \& Wu, 2019). Meanwhile, there is ample evidence in the literature showing that on the whole commuting time is rising in urban China (Day \& Cervero, 2010; Li, 2010; Sun et al., 2017; Wang \& Chai, 2009; Yang et al., 2017).

Uneven job decentralization contributes to the growing jobs-housing imbalance in urban China. With economic growth and the effort to upgrade industries, manufacturing facilities are moved out from the central areas, and residents are also removed to indemnification housing in suburban areas (Lin \& Wang, 2009; Wei \& Leung, 2005). Also, for environmental protection and because of high land prices in the central urban area, manufacturing, and concomitant job opportunities, have been decentralized as well (Gao, Liu, \& Dunford, 2014). Also, job decentralization in China is driven by restructuring policies such as the development of the new urban towns and development zones (Gao et al., 2014; Huang \& Wei, 2016; Qi, Fan, Sun, \& Hu, 2018; Wei \& Leung, 2005; Yang et al., 2017; Yuan, Wei, Chen, \& Jin, 2010). For example, development zones lead to highly concentrated employment clusters that dramatically reshape the urban structure. Due to the typical land-use planning, there is limited space for residential land within the development zones, which exacerbates the jobs-housing imbalance. For example, Zhou, Wang, Cao, and Wang (2017) found that the over-supply of industrial land, and limited residential land and public urban amenities, lead to longer commuting time and increasing use of automobiles in Suzhou Industrial Park in Suzhou, China.

\subsection{Summary}

Some gaps remain in the literature on the spatial restructuring of locational patterns of residences and workplaces, as well as jobs-housing imbalance in urban China. First, although urban inequality is severe in China, little attention has been paid to local variations of the mechanism of jobs-housing imbalance within urban areas, as most of the current studies focus on the whole city (Fan et al., 2014; Han et al., 
2015; Sun et al., 2017; Wang \& Chai, 2009). Second, state planning efforts, such as the establishment of development zones, significantly contribute to the concentration of manufacturing opportunities in the suburbs (Gu \& Shen, 2003; Li et al., 2014; Wei \& Leung, 2005). However, only the Zhou et al. study (2017) implemented a qualitative study to identify the impact of the land use planning in the development zones on the people's commuting behavior in an industrial park in Suzhou. The state's efforts cannot be understood based on a single study of the land use planning in Suzhou Industry Park. Third, housing affordability has become a critical issue in China's global cities, such as Beijing and Shanghai, because it influences the jobs-housing imbalance. However, little attention has been paid to how skyrocketing high housing prices contribute to a jobs-housing imbalance. Fourth, China's cities typically exhibit a monocentric urban structure, characterized by highly concentrated job opportunities and a population that is sprawling due to high housing prices (Li et al., 2019a). Thus, China's city model is different from the ones in western countries, and the mechanism of the jobs-housing imbalance may be unique. Finally, regions with rapidly growing floating populations are attractive to some manufacturers, and this can boost local economic growth. Current studies only focus on the floating population concerning jobs-housing imbalance while ignoring the stimulus to economic growth provided by an expanding low-wage labor pool (Fan, et al, 2014; Zhou et al., 2016).

\section{Data and methodology}

\subsection{Study area and data}

Most of the research on jobs-housing imbalance or commuting issues in China is conducted in Beijing, the capital of China. Shanghai, as China's leading global city, which has been experiencing rapid population growth and urban land expansion (Li et al., 2014), is not well studied. In this study, we focus on the mainland of Shanghai (Figure 1), including 18 districts of Shanghai, excluding Chongming. These districts are classified into four parts, the traditional city proper area (Huangpu, Luwan, and Jingan), expanded central city area (Xuhui, Changning, Putuo, Zhabei, Hongkou, and Yangpu), inner-suburban area (Pudong, Minhang, and Boshan) and outer-suburban area (Wei, Bi, Wang, \& Ning, 2016). The other districts compose the outer-suburban area, including Jinshan, Fengxian, Songjiang, Qingpu, and Jiading. Each district contains several subdistricts.

The population data was provided by the Sixth Census at the subdistrict level in 2010, while the employment data comes from the Third Economic Census in 2013. They are the most recently available population and employment datasets at the subdistrict level (the Fourth Economic Census in 2018 has not been released), which are highly reliable and popular in identifying jobs-housing imbalance or job accessibility (Fan et al., 2014; Hu, Fan \& Sun, 2017). Compared to other datasets such as surveys (Zhou et al., 2014), census data from the Chinese government is reliable and accurate to estimate jobs-housing imbalance. Also, the spatial distributions of population and employment in Shanghai have shown a stable pattern since 2010. The current population in Shanghai is about 24 million, while the population in 2010 was already over 23 million (SSB, 2019). Furthermore, the spatial distributions of population and employment do not change much in recent years compared to the Li et al. study (2019c) based on an open dataset in Shanghai. Thus, the research outcomes based on these datasets are still meaningful to explore the determinants of jobs-housing imbalance in Shanghai.

The economic census data contains the company information, including the address, the number of employees, and the year established. The sociodemographic data such as the size and status at the district level are derived from the Shanghai Statistical Yearbook (SSB, 2014). Furthermore, a housing dataset, including housing prices, is provided by Lianjia.com, which is one of the largest real-estate trans- 
action platforms in China. The housing data collected from Lianjia.com cover the whole of Shanghai, and a previous study suggests that this dataset can appropriately reflect the spatial differentials of the housing market in Shanghai (Li et al., 2019a \& b).

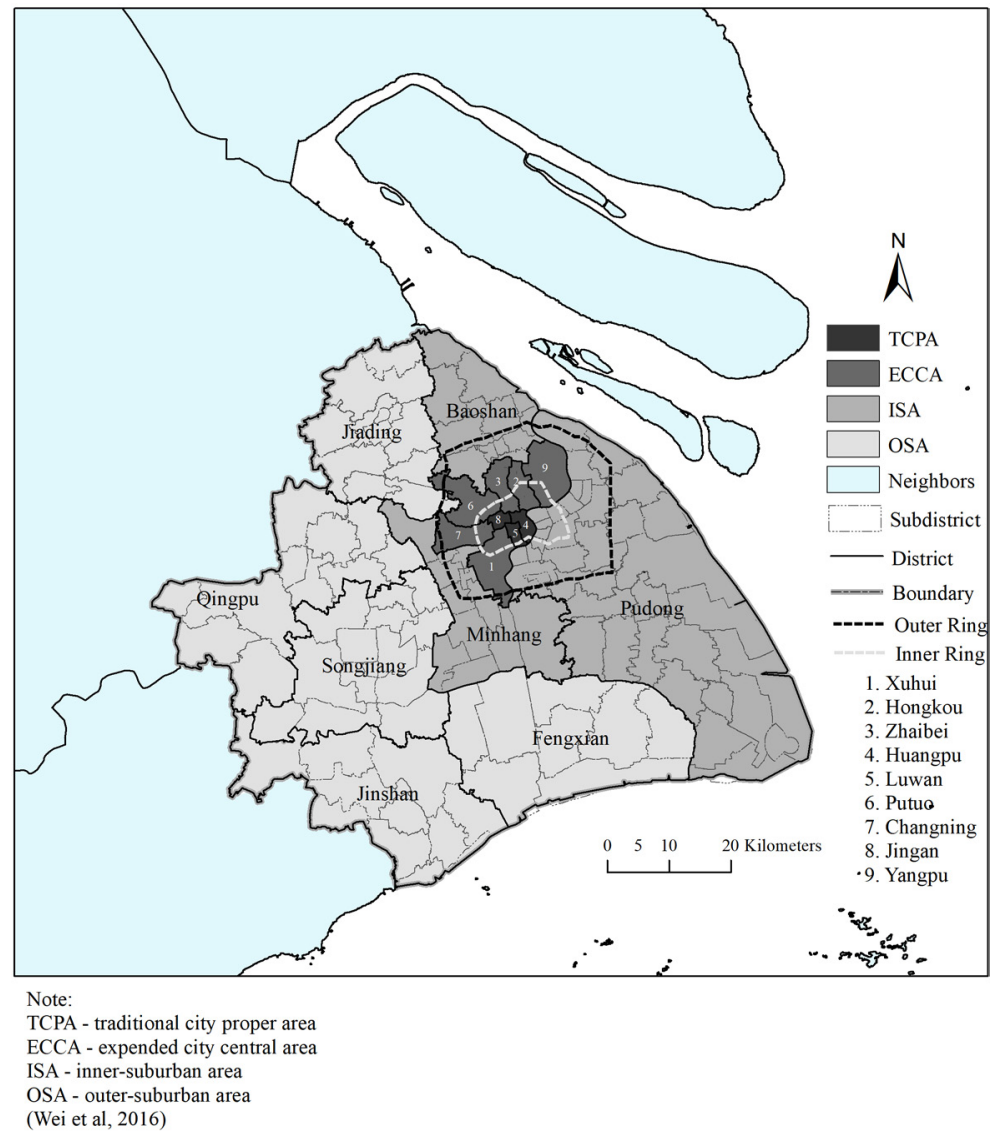

Figure 1. Study area

\subsection{Spatial mismatch indexes}

In this study, we use the spatial mismatch between employment and population to capture jobshousing imbalance at subdistrict level (Fan et al., 2014; Wang et al., 2011). The spatial mismatch index, which is derived from the dissimilarity index, describes the spatial relationship between employment and population in a certain region. Using spatial analytical tools, scholars try to improve the spatial mismatch index by adding a spatial weight matrix. The general form of the new spatial mismatch index can be expressed as Equation 1. In this formula, $\mathrm{C}$ represents a spatial weight matrix to measure travel cost between residences and job opportunities, which can be specified as a nonlinear equation with a threshold such as 10-mile travel distance or 60-minutes travel time (Fan et al., 2014). In this research, the spatial weight matrix $\mathrm{C}$ is calculated based on the topological relationship between the subdistricts.

$$
\begin{gathered}
S M I_{K}=\frac{1}{2} * \sum_{i=1}^{n}\left|\frac{C P_{i}}{\sum_{i=1}^{n} C P_{i}}-\frac{C E_{i}}{\sum_{i=1}^{n} C E_{i}}\right| \\
C=\left\{\begin{array}{l}
1 ; \text { If town } i \text { are closed to town } K \\
0 ; \text { if town i are far from town } K
\end{array}\right.
\end{gathered}
$$


For subdistrict K, we consider the population $(P)$ and job opportunities $(E)$ of the subdistricts that are close to subdistrict $\mathrm{K}$, to calculate the spatial mismatch index. We define "close" based on the adjacency relation between the subdistricts as following:

For any subdistrict, if the subdistrict that shares boundaries with subdistrict $\mathrm{K}$, it is included in the group K1. Then, for any other subdistrict, if the subdistrict that shares boundaries with subdistrict K1, it is included in the group K2. The subdistricts in group K1 and K2 are the ones "close" to the target K.

This method is similar to the actual growth of the urban area. It helps get a better geographical unit with a low factual dimension, which also corresponds to the natural growth of the urban area (Fotheringham, Batty, \& Longley, 1989; Shen, 2002). The spatial mismatch index is calculated at the subdistrict level in this study, and each subdistrict is assigned with one value of the spatial mismatch index. Compared to previous studies on jobs-housing imbalance, which calculate a quantitative measure for the whole city (Stoll, 2005; Stoll \& Covington, 2012; Wang et al., 2011), this spatial mismatch index could reveal the spatial variance of jobs-housing imbalance within the urban area. Also, subdistrict level data is the minimum analytical unit to examine the overall pattern of jobs-housing imbalance in urban China.

We do not use travel time/distance to create spatial weight matrix because travel distance and travel time are both sensitive to travel mode choice and the coverage of transportation facilities. So far the coverage of the metro system is poor in suburban Shanghai and people still rely on the bus. Also, sharing bikes is getting popular in urban China, and combined travel modes make it hard to estimate commuting distance/time. Thus, we build the spatial weight matrix using neighbors. In the suburban area, the subdistricts are larger than the ones in the central urban area and going through the subdistricts needs longer commuting distance. However, the travel speed is faster in the suburban area than in the central urban area because of the heavy traffic in the central urban area. Thus, using a neighbor to define a spatial weight matrix creates an adaptive spatial region for analysis. In the suburban area, the commuting distance is longer, while the commuting time might be shorter. In the central urban area, the commuting distance is short, but it might take more time because of heavy traffic. For subdistrict $\mathrm{K}$, we selected group $\mathrm{K} 1$ and $\mathrm{K} 2$ for analysis because the average commuting time of 40 minutes is expected to go through two subdistricts. Therefore, when the transportation data for estimating travel distance/time is not available, using neighbors to define a spatial weight matrix is a good option.

\subsection{Multilevel modeling and geographically weighted regression}

In addition to identifying the pattern of jobs-housing imbalance in Shanghai, we also explore its causes. This study considers four aspects: social factors, urban structure, regional planning, and urban amenities. Social factors include the sociodemographic status of the local population. The urban structure includes such factors as population density and housing price. The regional planning factor refers to the development zones which largely influenced by government policy. Urban amenities consist of public transportation and street connectivity. The theoretical model can be expressed as follows (Equation 2):

$y(s)=F(U, S, R, A)+\varepsilon$

Where $y(s)$ represents the jobs-housing imbalance, $F(U, S, R, A)$ is a functional form with urban structure $(U)$, social factors $(S)$, regional planning $(R)$, and urban amenities $(A) . \varepsilon$ is the residual term.

Three types of regression are adopted in this study: ordinary least squares, multilevel models, and geographically weighted regression. The estimation of ordinary least regression can be obtained from Equation 3. 
$Y=C+F(U, S, R, A) \beta+\varepsilon, \varepsilon \sim N\left(0, \sigma^{2} \mathrm{I}\right)$

Where $Y$ is the dependent variable, $C$ is the constant, $F()$ contains the independent variables, and $\beta$ is the estimations for the independent variables. $\mathcal{E}$ is the error term.

The urban land of Shanghai has expanded a lot in recent years and the huge development gap exists between the central urban area and the urban periphery. Also, there are 17 districts in Shanghai, and each district is unique in its urban structure, which is comprehensively influenced by history and government policy. For example, the Pudong district is unique in that it is a sub-province district, and this district attracts a large population and substantial foreign direct investment (FDI). This uniqueness contributes to urban inequality within Shanghai, and the jobs-housing imbalance in different districts varies along with urban structure and social factors. Furthermore, the result of the Hauseman test suggests that the dataset in this paper is "nested" within the districts. The spatial effect caused by the fixed effect can be partially explained by the multilevel model (MLM). There are two levels in the dataset, the subdistrict level (level 1) and the district level (level 2), and the MLM can partition variance between each level and explain the variance within each level (Tian, Wei, \& Li, 2017). The two-level random intercept HLM equation is as follows:

$Y_{i j}=\beta_{0 j}+\beta_{1 j} F(U, S, R, A)+r_{i j}$

$\beta_{-0 j}=\gamma_{00}+\mu_{0 j}$

$\beta_{1 j}=\gamma_{10}+\mu_{1 j}$

Where $Y_{i j}$ is the dependent variable, spatial mismatch index, $i$ refers to the subdistrict, and $j$ refers to the district.

$\beta_{0 j}$ is the intercept of $Y_{i j}$ when all the variables in $F(U, S, R, A)$ are 0 .

$\mathrm{F}(\mathrm{U}, \mathrm{S}, \mathrm{R}, \mathrm{A})$ is a matrix of dependent variables,

$\beta_{1 j}$ is the coefficient for $X_{i j}$.

$r_{i j}$ is the error term.

$\gamma_{00}$ is the average of intercept for the district $j$

$\mu_{0 j}$ is the random error term for the $j^{\text {th }}$ district

$\gamma_{10}$ is the fixed part of coefficients for $X_{i j}$

$\mu_{1 j}$ is the random error term for the slope

Furthermore, to control spatial heterogeneity, geographically weighted regression (GWR) is employed to measure the local variation among regression parameters. There are two reasons that the GWR model is employed in this study. First, the previous two regression models can reflect the overall result of the estimations. However, urban inequality makes the mechanism of jobs-housing imbalance not consistent among all the districts. For example, the current Pudong district is the combination of the traditional Pudong district (Northern part of current Pudong) and the Nanhui district (Southern part of the current Pudong). The North-south division still can be found in the current Pudong district, e.g., in differences in housing price ( $\mathrm{Li}$ et al., 2019a). Second, in the spatial test, we found a significant global Moran's I as 0.416 , which indicates strong spatial dependence. Hence, spatial heterogeneity should not be ignored. In its most basic form, the GWR model takes the following equation (Equation 5)

$Y_{i}=C_{i}+\sum_{k} \beta_{k i} F(U, S, R, A)_{k i}+\varepsilon$

Where $Y_{i}$ is people's minutes spent walking to be regressed, $C_{i}$ is constant, $\beta_{k i}$ is the parameter for individual explanatory variables, and $F(U, S, R, A)_{k i}(k=1,2,3 \ldots n), \varepsilon_{i}$ is the error term. The adaptive kernel 
is employed as the kernel function (Fotheringham, Brunsdon, \& Charlton, 2002). This model considers spatial heterogeneity and manifests the complex local variation of regression parameters. With the GWR model, it is easier to achieve a better understanding of the determinants and their influence.

\subsection{Variables}

Several variables are included in regression analysis, and the definition and description of the variables are given in Table 1. The independent variables are classified into four categories: sociodemographic status, urban structure, regional planning, and urban amenities. Due to limited data availability, some data are at the subdistrict level, and other data are at the district level. The sociodemographic status contains information about gender and age, the percentage of floating population, and people moving out of the districts. People aged 19-59 constitute the working-age population group, and the percentage of people aged 19-59 is included in this model.

Unlike previous studies that focus on rural migrant workers (Fan et al., 2014; Feng et al., 2002), this paper pays particular attention to the floating population for the following reasons. First, Wu and Logan (2016) suggest that rural migrants gather in urban villages that are close to job centers because they cannot afford the cost of transportation. Educated newcomers, instead of the poorly educated and low-income rural migrants, make up the majority of the floating population, who are the most vulnerable group to jobs-housing imbalance and long commuting time (Li et al., 2019b). Also, the data on rural migrants is limited because the population census in China only provides the data for the floating population as a whole. Considering the large portion of the floating population in Shanghai with high mobility, we include the floating population growth rate as an important demographic factor.

The variables related to the urban structure include the housing prices and population density. Monocentric urban structure and polycentric urban structure are two common urban structures, and the urban structure of Shanghai is now transforming from monocentric to polycentric. From the perspective of morphology, the spatial distribution of the population is most used to identify the urban structure. Liu and Wang (2016) use the spatial distribution of population to identify polycentricity in 318 cities in China and achieve favorable outcomes. Thus, we employ population density as an indicator of urban structure. In addition, housing prices are tightly associated with urban structure with respect to residential differentiation and division of submarkets ( $\mathrm{Li}$ et al., 2019a). Housing prices are sensitive to the transformation of urban structure, and polycentric urban development is suggested to influence housing prices (Wen \& Tao, 2015). Thus, as the housing prices skyrocket in Shanghai, housing prices should not be ignored as a critical determinant of urban structure. We obtained the housing price data from Lianjia.com, which is a community-level dataset, and the average value of housing prices for each district is taken as one variable.

Regional planning and urban amenities have not drawn much attention in previous studies on the jobs-housing imbalance. In this study, four factors have been taken into consideration, the density of bus stops, the density of metro stations, street connectivity, and the development zones. Figure 2 shows the locations of the metro stations, and the traditional city proper area (TCPA), expanded central city area (ECCA), and inner-suburban area (ISA) are provided with the metro stations. The traditional theory suggests that a well-developed transportation system provides a solution to the jobs-housing imbalance (Kain, 1992). Hence, understanding the relationship between public transportation and jobs-housing imbalance is helpful for further policy suggestions. With respect to regional planning policy, we focus on the impacts of development zones. Development zones play an important role in attracting FDI, which can generate a lot of job opportunities (Wong \& Tang, 2005; Wei \& Leung, 2005). In this study, we calculate the percentage of the area that is covered by development zones as an explanatory variable. Furthermore, the percentage of residential apartments among all the buildings can reflect the availability 
of residences since the residential apartment provides most of the living space in Shanghai. Thus, we consider the percentage of residential apartments among all the buildings in the model. Also, because of uneven development in Shanghai, this paper employs a multilevel model to consider the effects of China's hierarchical administrative system.

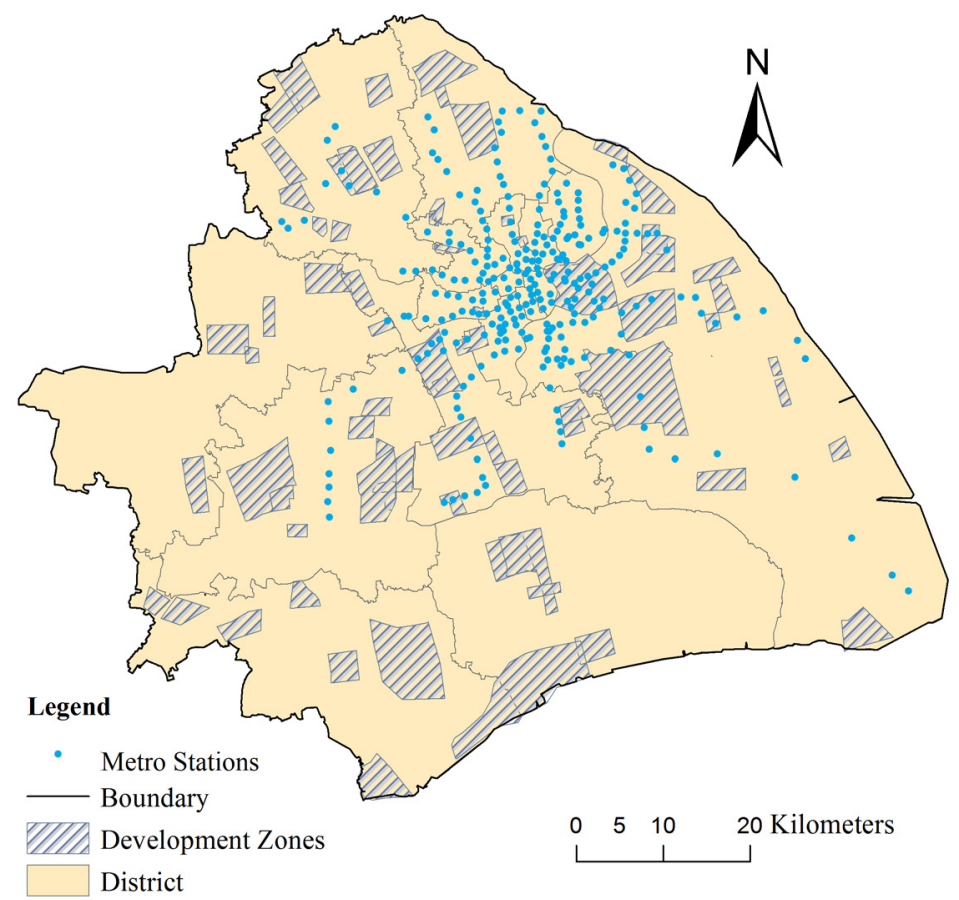

Figure 2. Locations of development zones and metro stations 
Table 1. Description of variables

\begin{tabular}{|c|c|}
\hline Description & Description \\
\hline \multicolumn{2}{|c|}{ Dependent Variable } \\
\hline Spatial Mismatch Index & Authors' calculation (Eq.2) \\
\hline \multicolumn{2}{|c|}{ Independent Variables } \\
\hline \multicolumn{2}{|c|}{ District level } \\
\hline Percentage of population flow out & Population flow out divided by total population \\
\hline Percentage of people aging from 18-59 & Population aging from 18-59 divided by total population \\
\hline Percentage of male residents & Number of men divided by total population \\
\hline Percentage of residential apartments & $\begin{array}{l}\text { Number of residential apartments divided by total number of } \\
\text { apartments }\end{array}$ \\
\hline Population density & Number of total population divided by area $\left(m^{2}\right)$ \\
\hline \multicolumn{2}{|c|}{ Subdistrict level } \\
\hline Percentage of floating population & Number of floating population divided by total population \\
\hline Growth rate of floating population & Growth rate of floating population from 2000 to 2010 \\
\hline Housing price & Average value of housing price in the subdistricts \\
\hline Development zones & $\begin{array}{l}\text { Total area of development zones located in the subdistricts } \\
\text { divided by the total area of the subdistricts }\end{array}$ \\
\hline Density of metro stations & $\begin{array}{l}\text { Number of the subway stations divided by total area of the } \\
\text { subdistricts }\end{array}$ \\
\hline Density of intersections & $\begin{array}{l}\text { Number of street intersections divided by total area of the } \\
\text { subdistricts }\end{array}$ \\
\hline Density of bus stops & Number of bus stops divided by total area of the subdistricts \\
\hline
\end{tabular}

\section{$4 \quad$ Population, job opportunities and spatial imbalance in Shanghai}

Although the urban area in Shanghai expanded dramatically in recent years, the urban structure of Shanghai is still highly concentrated (Li, Wei, \& Huang, 2014). Densities of population and job opportunities are essential measures of urban structure. Figure 3 contains two maps that present the spatial distribution of population and job opportunities. The population is highly concentrated in the central urban area, while there are some job centers detected on the periphery regions. Furthermore, Table 2 suggests that only a few representatives of the floating population live in the ECCA, especially in the Pudong district. As regards housing price (Figure 4 (c)), a core-periphery pattern also can be detected. Housing prices in the central city and the Pudong district are extremely high, which means the TCPA can only provide residences for rich people. People have to live in the ECCA or the urban periphery while they are working in TCPA. ECCA also has many job opportunities. However, the size of the population is vast there, with high population density. The large population in ECCA could compensate for the labor force requirement in TCPA since they are close to each other. The high housing prices and limited job opportunities in the ECCA can explain the lack of a floating population. 


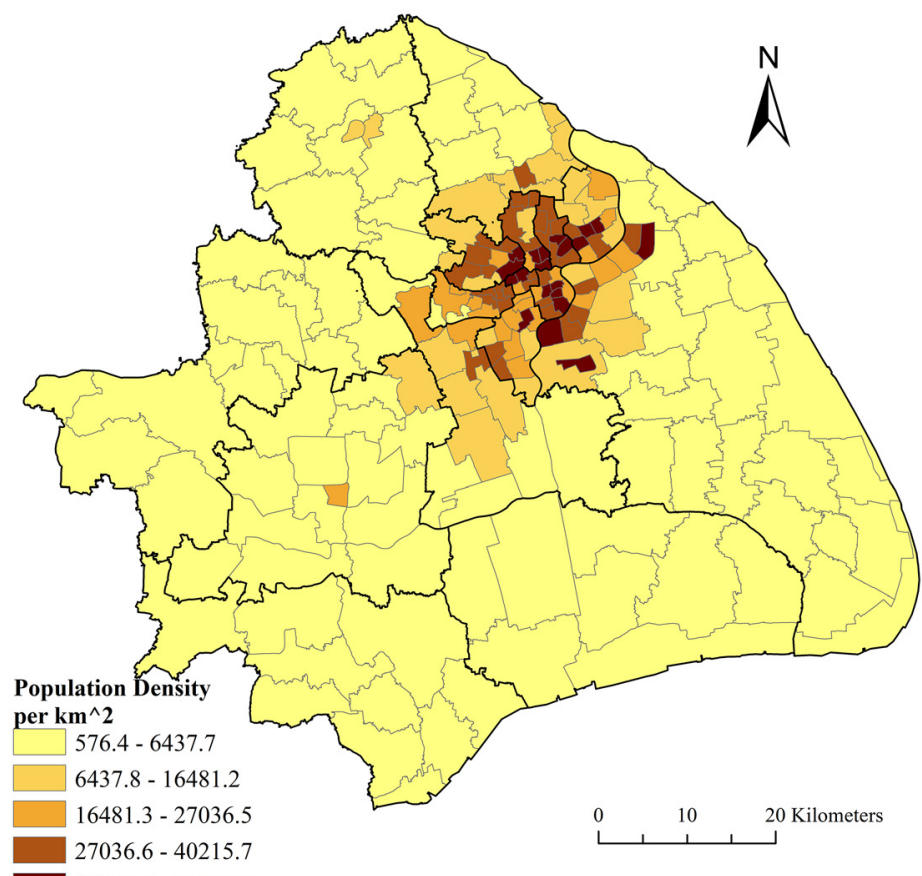

(a)

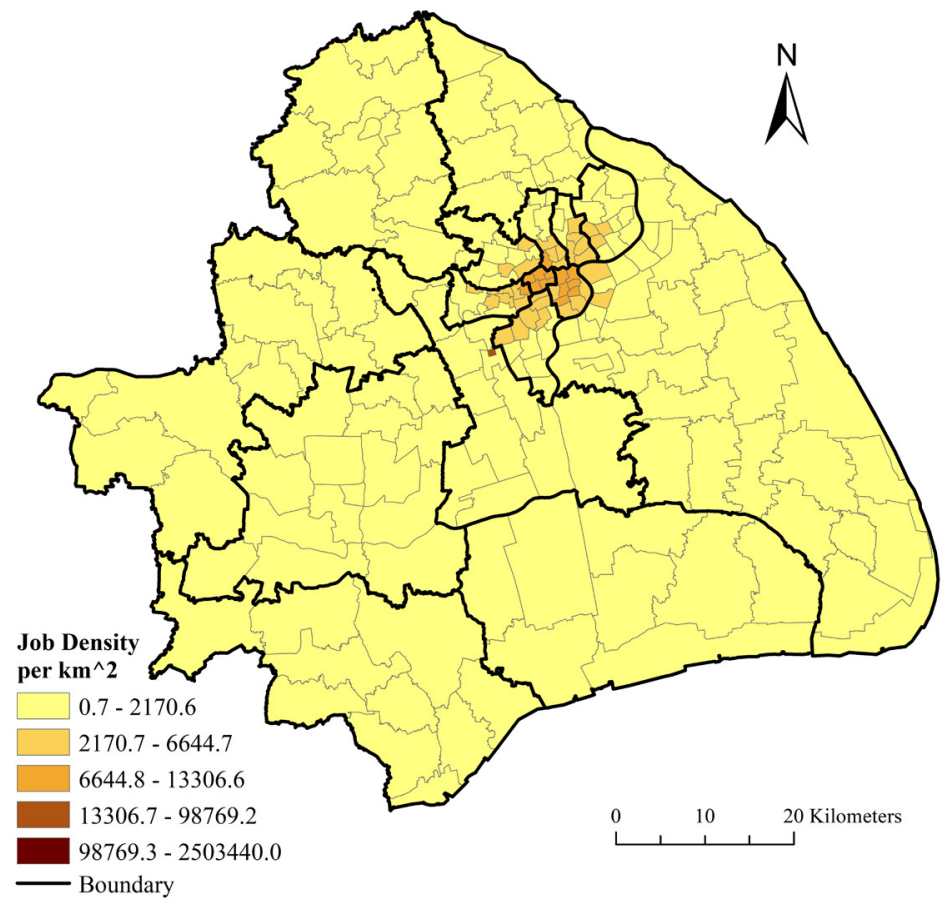

(b)

Figure 3. Maps (a) spatial distribution of population; (b) spatial distribution of job opportunities 
Table 2. Summary of job opportunities and population in 2013

\begin{tabular}{lccccc}
\hline & TCPA & ECCA & ISA & OSA & Pudong \\
\hline Job Opportunities & 925,458 & $1,460,173$ & $1,599,246$ & $1,851,060$ & 921,693 \\
Population & 401,083 & $6,003,601$ & $9,728,193$ & $5,950,524$ & $5,044,430$ \\
Floating Population & 257,283 & $1,632,073$ & $4,095,273$ & $3,199,365$ & 826,494 \\
Area $\left(\mathbf{k m}^{2}\right)$ & 28.08 & 260.85 & $1,830.72$ & $3,013.93$ & $1,390.62$ \\
Job Density & $32,957.91$ & $5,597.75$ & 873.56 & 614.17 & 662.79 \\
Population Density & $14,283.58$ & $23,015.53$ & $5,313.86$ & $1,974.34$ & $3,627.47$ \\
Floating Population & $9,162.5$ & $6,256.74$ & $2,236.97$ & $1,061.52$ & 594.33 \\
Density & & & & & \\
\hline
\end{tabular}

* Data source: China’s demographic census at town level in 2012; enterprise registered survey in Shanghai, 2013

Note: TCPA: traditional city proper area; ECCA: expanded city central area; ISA: inner-suburban area; OSA: outer-suburban area.

ISA and outer suburban area (OSA) are two regions with a relatively low density of both job opportunities and population. However, in recent years, the ISA and the OSA have been experiencing rapid population growth. Figure 4 (a) shows that the concentration of population growth can be mainly found on the boundary of ISA, especially in the Minghang and Songjiang districts. The development of university towns contributed to the high growth rate of population, and in recent decades, many universities established new campuses in Songjiang and Minhang, such as Shanghai Jiao Tong University and Eastern China Normal University. The university towns are treated as "new cities" by the Chinese government, and considerable efforts have been devoted to the development of university towns (Ye, Chen, Chen, \& Guo, 2014). Moreover, increasing job opportunities in service-based industries that are not knowledge-based also led to a high growth rate of the floating population on the edge of Shanghai, as Figure 4 (b) suggests. Since the 1990s, manufacturing firms have experienced a process of decentralization in most of China's big cities. For Shanghai, the newly established development zones, such as the Fengxian economic development zone, created the proper environment for this decentralization (Feng et al., 2002; Gu \& Shen, 2003).

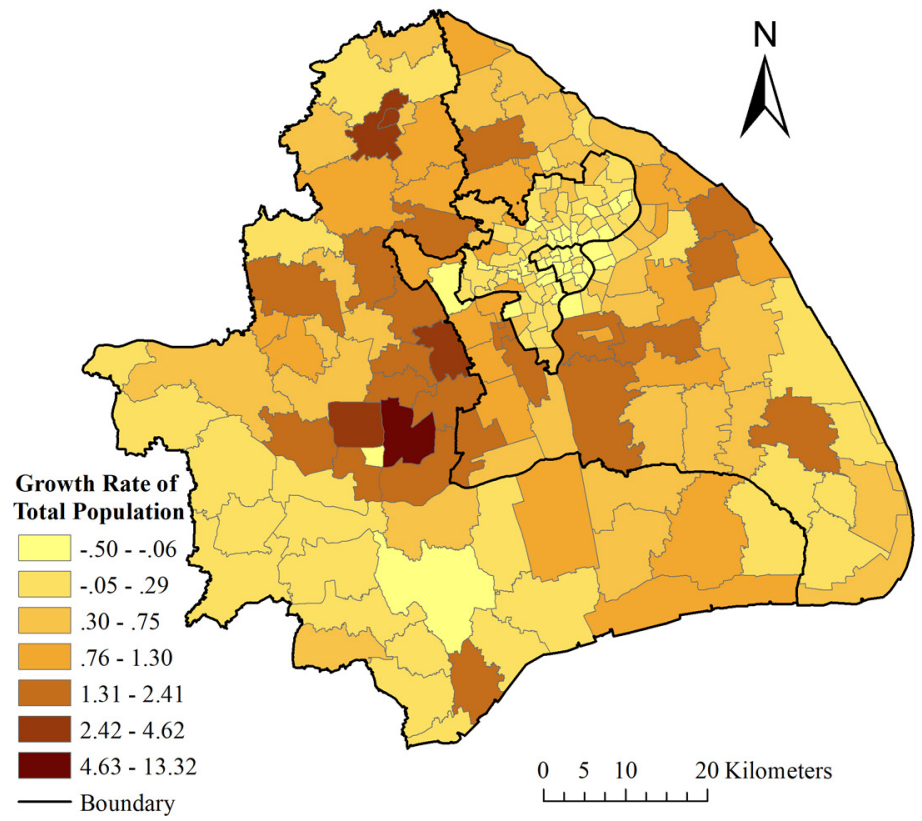

(a) 


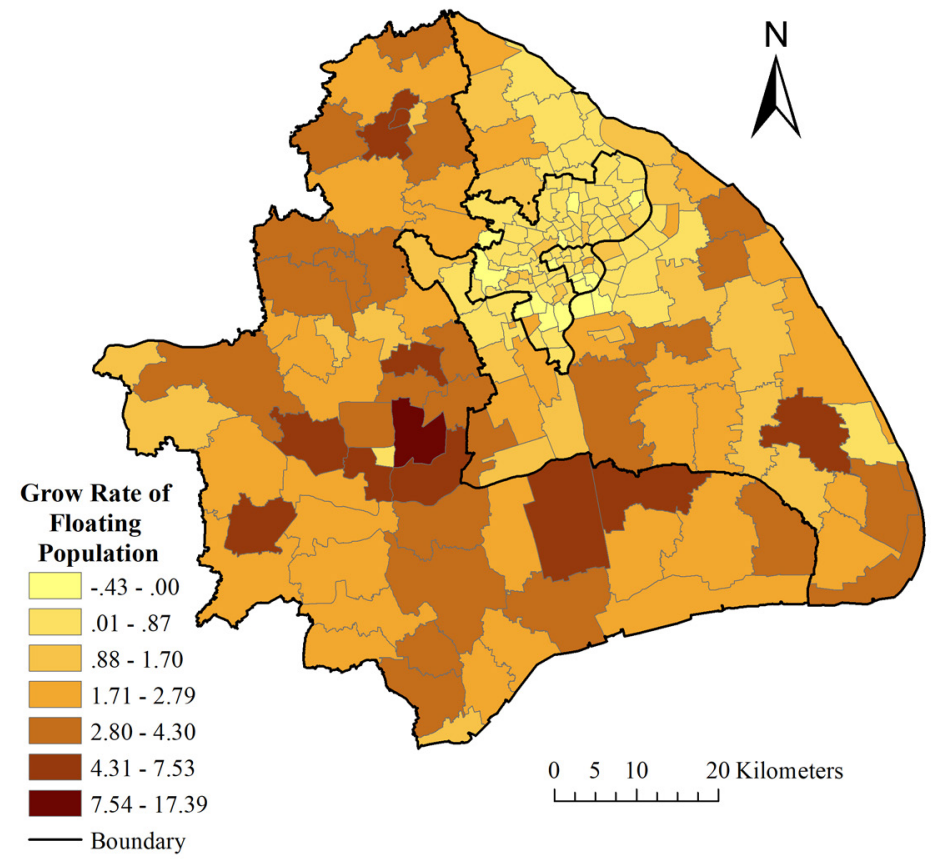

(b)

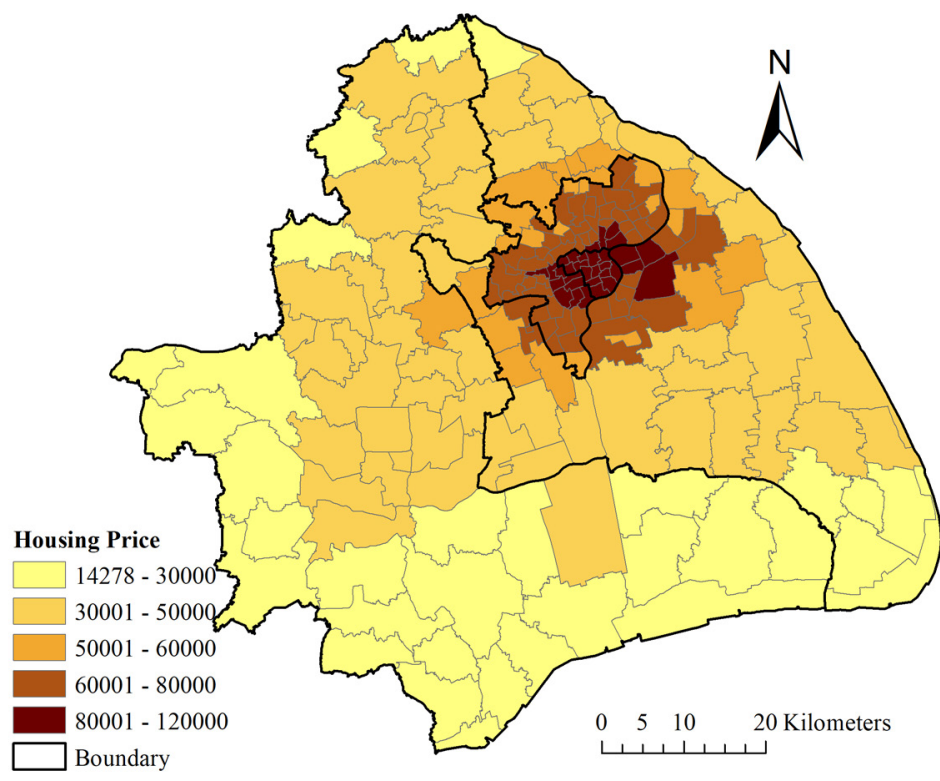

(c)

Figure 4. (a) Growth rate of total population; (b) growth rate of floating population (c) housing price

Population growth rates in TCPA and ECCA are low, and the growth rate of population in some subdistricts has even been negative. Shanghai is the financial center of China, and in central city areas such as Lujiazui District, there is a high concentration of financial and service industries. With the decentralization of manufacturing (Feng et al., 2002; Gu \& Shen, 2003), the central area requires fewer laborers than before, which might contribute to the negative growth rate of population. In addition, unaffordable housing prices also constitute a barrier to keeping people from moving to the central urban 
area. Figure 4 (c) shows the spatial distribution of housing prices in Shanghai, and extremely high housing prices can be detected in TCPA, where housing price reached about 80,000 Yuan (about \$12,000) per $\mathrm{m}^{2}$. Housing prices in ISA and OSA are much lower, and even in such fast-growing districts as Songjiang and Minghang, the housing value is about 30,000 Yuan (about \$4500) per $\mathrm{m}^{2}$. Hence, considering the geographies of job opportunities and housing prices, the Songjiang district and Minghang district become the ideal places for the well-educated floating population.

The statistics for Pudong district are also provided in Table 2. Historically, the northwestern part of the new Pudong district was the first modern financial center of Shanghai; Lujiazui and the new free trade zone were located in the northern part of the Pudong district. The southern part used to be named the Nanhui district. To contribute to the growth and development of Pudong, Nanhui District was combined with the traditional Pudong district into the current Pudong district in 2009. Because the combination happened fairly recently, there is still a significant difference between southern Pudong and northern Pudong with respect to housing prices and population growth. The population density is high in the northern part of the new Pudong district, and the population density in the southern part is as low as the population density in OSA.

Combining the spatial patterns of job opportunities and population in Shanghai, Figure 5 shows the value of the spatial mismatch index. The jobs-housing relationship shows a ring pattern, and jobshousing imbalance mainly happens in the middle ring, on the periphery of the expanded central urban area. This pattern is caused by the fact that job opportunities are concentrated in the central urban area, while the expanded central urban areas mainly provide residential sites. This pattern also reveals the decentralization of population in the expanded urban area, which makes the area attractive for development zones and university towns (Wang \& Chai, 2009; Ye et al., 2014; Zhou et al., 2017). As the urban land of Shanghai keeps expanding (Li et al., 2014), the middle ring is expected to provide residences to the workers in both the outer ring and inner ring.

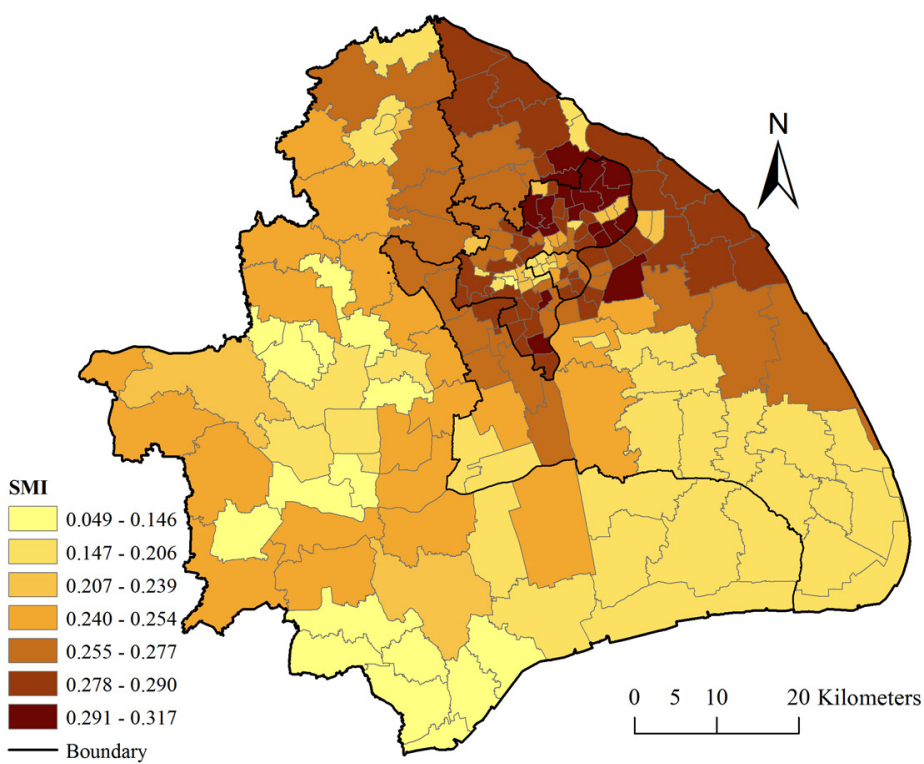

Figure 5. Spatial mismatch index in Shanghai at the subdistrict-level 


\section{Determinants of jobs-housing imbalance}

Much research has been done on jobs-housing imbalance and the determinants in developed countries, but that experience cannot be directly transplanted into the context of China. Only a few studies have addressed the jobs-housing imbalance in China and its impact (Wang et al., 2011; Xu et al., 2013; Zhou et al., 2014; Zhou, Chen $\&$ Zhang, 2016; Zhou et al., 2017). To further quantify how social factors, urban structure and growth, regional planning, and the administrative system collectively shape the jobs-housing imbalance in Shanghai, a multivariate regression analysis was conducted. Table 3 shows the results of the multilevel regression model and the GWR model. The variance inflation factor (VIF) value for each variable is below three, which means that the problem of multicollinearity is insignificant. The $\mathrm{R}^{2}$ of the multilevel model is much higher than the $\mathrm{R}^{2}$ of OLS, which suggests that geographic scales and administrative hierarchy matter in explaining the jobs-housing imbalance in Shanghai. Also, in the multilevel model, about $21 \%$ of the variance within cities and $74 \%$ of the variance between cities has been explained. Thus, the administrative hierarchy is vital in explaining the jobs-housing imbalance in Shanghai.

Table 3. Regression result

\begin{tabular}{l|c|c}
\hline \multicolumn{1}{c}{ Variables } & Coefficients MLM & GWR(Mean) \\
\hline \multicolumn{2}{c|}{ District level } \\
\hline Population flow out & $1.220 \mathrm{e}-6$ & $-3.700 \mathrm{e}-6$ \\
Percentage of people aging from 18-59 & -0.788 & -0.637 \\
Percentage of men & 0.096 & 0.455 \\
Percentage of housing for living & $0.411^{* *}$ & 0.237 \\
Population density & $5.234 \mathrm{e}-7$ & $8.973 \mathrm{e}-7$ \\
\hline & Subdistrict level \\
\hline Percentage of floating population & $0.038^{* *}$ & 0.030 \\
Growth rate of floating population & $-0.004^{* *}$ & -0.007 \\
Housing price & $9.234 \mathrm{e}-7^{* *}$ & $8.385 \mathrm{e}-7$ \\
Development zones & $1.243 \mathrm{e}-7^{*}$ & $3.324 \mathrm{e}-8$ \\
Density of metro stations & -0.014 & -0.016 \\
Density of intersections & $2.514 \mathrm{e}-4$ & $5.861 \mathrm{e}-4$ \\
Density of bus stops & $-2.691 \mathrm{e}-4$ & $-4.892 \mathrm{e}-4$ \\
\hline
\end{tabular}

Note: ${ }^{* * *}$ Significant at 0.01 level; ${ }^{* *}$ Significant at 0.05 level; ${ }^{*}$ Significant at 0.1 level.

\subsection{The result of MLM}

According to the results of MLM, the percentage of people aged from 18 to 59, the percentage of residential properties, and the percentage of the floating population are the three significant variables according to the OLS model. People aged from 18 to 59 are the leading working-age population group, and the negative coefficient suggests that they are likely to live in the area of jobs-housing balance. The positive coefficient for the percentage of residences suggests that the residential land is enough in 
most of the region, and increasing job opportunities could relief jobs-housing imbalance problem. The percentage of the floating population is significant in the regression models, and the subdistricts with more floating populations tend to have a higher degree of jobs-housing imbalance. Thus, compared to the registered population, the floating population is more likely to suffer from jobs-housing imbalance. Residential availability is an essential concern for the floating population when they look for jobs.

We employed four variables to represent the urban structure in Shanghai. Unlike the coefficient of floating population percentage, the coefficient for growth rate of floating population is negative in the regression models. Since Shanghai is the financial center of China, the job opportunities in the core are mainly for high-skill occupations such as financial services, and the manufacturing industry has moved to the periphery of Shanghai. Figure 4 (b) suggests that the growth of the floating population mainly happens in the OSA in Shanghai. The OSA is under-developed, and there are not many people living there. However, some development zones create a lot of job opportunities, which triggers an inflow of the floating population.

The positive coefficient of housing price in the regression model supports our assumption that high property value leads to jobs-housing imbalance. Housing price is the most fundamental factor in selecting residential sites because people choose homes according to their income (Campbell, Kim, \& Eckerd, 2014). As the Danwei system is diminishing in China, high land value or housing price creates an imbalanced distribution between residences and job opportunities. The high cost of housing may make it difficult to find an apartment close to job opportunities. The relatively poor "floating" workers have to find affordable homes, which are usually distant from their workplaces. Thus, the development of affordable housing and the public rent housing system could play a key role in providing residences for migrant workers in the future.

Moreover, the establishment of development zones exacerbates the jobs-housing imbalance. Development zones, such as high-tech parks and duty-free zones, aim to attract foreign direct investment, which generates a large number of job opportunities (Wei \& Leung, 2005). In 2014, there were 23 nation-level development zones and 55 province-level development zones in Shanghai. To maximize the use of development zones, most of the land in development zones is designated for industrial or commercial use rather than residential. The jobs-housing imbalance is obvious since there is limited living space for workers. Hence, mixed land-use planning in development zones is urgently needed to relieve the jobs-housing imbalance problem. Or the government should provide convenient transportation between the development zones and the affordable houses.

A well-connected street network or a good public transit system can relieve the jobs-housing imbalance problem (Ong \& Miller, 2005). The regression models show that road connectivity is high in the jobs-housing imbalanced regions. Thus, with respect to road connectivity, urban planners in Shanghai are trying to deal with the current jobs-housing imbalance problem. If supported by a well-designed road network and urban transit system, people working in the central urban area could reside in the suburban region and enjoy short commutes. However, the model results show that there are not enough metro stations in the jobs-housing imbalance areas. Currently, the expanded central urban area provides most of the residences, and the connection between the expanded central urban area and the suburban area is weak.

\subsection{The result of GWR}

The geographically weighted regression was employed to examine spatial heterogeneity. The mean values of the coefficients are attached in Table 3. We could see that the coefficients of the variables like the growth rate of the floating population are different from the ones in the MLM. Hence, the coefficients of population density (a), development zone (b), and percentage of the floating population (c) are pre- 
sented in Figure 6 to explore the spatial heterogeneity. Map (b) suggests that in northern-eastern Shanghai, in particular in the western part of Pudong district (without Nanhui) where many development zones are located, the subdistricts with more development zone coverage have a lower value of spatial mismatch index. Thus, in this region, the development zones contribute to jobs-housing balance which is opposite to other subdistricts and the previous finding in Suzhou (Zhou et al., 2017). In the northern Pudong district, many development zones have been established for decades, and the planning there is mature. In recent years, there are a large number of housing projects launched in the Pudong district, which provide residential sites for people working in the development zones. Also, the housing projects in the Pudong district have extremely high housing prices and good accessibility to public transportation (Li et al., 2019c). Thus, the Pudong district can serve as an example for creating more jobs-housing balanced communities for improving job accessibility in the development zones. Furthermore, the negative impact of development zones on jobs-housing imbalance is severe in the suburban regions of Shanghai, which are also less covered by the transportation system. Thus, a jobs-housing imbalance is a challenge for people working there.

Moreover, in the central urban region, which is highly developed, high population density contributes to jobs-housing imbalance (Figure 6 (a)). Unlike the general pattern in which there are more people than job opportunities, there are a huge number of job opportunities in the central urban region where the residential sites are expensive and limited. On the other hand, the coefficients of the floating population percentage are positive in most of the suburban regions in Shanghai. Since the floating population is socioeconomically disadvantaged, the limited living space near job opportunities makes it difficult for them to live in Shanghai, and it is also hard for them to afford the expense of commuting. Therefore, the local government should make more efforts to solve the jobs-housing imbalance problem for the floating population.

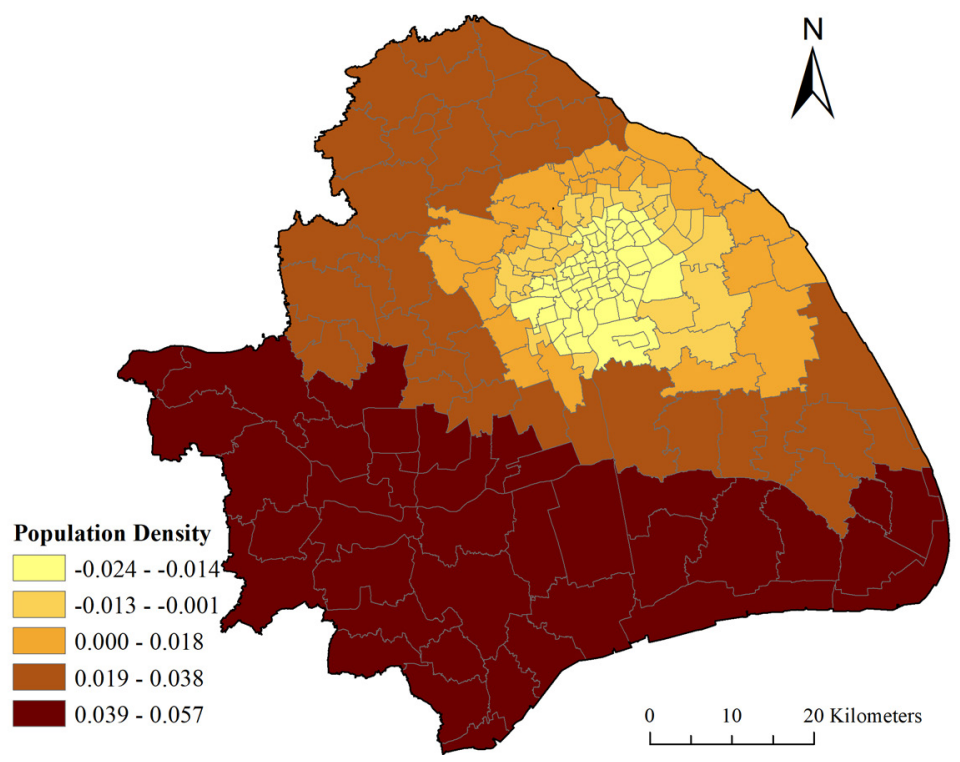

(a) 


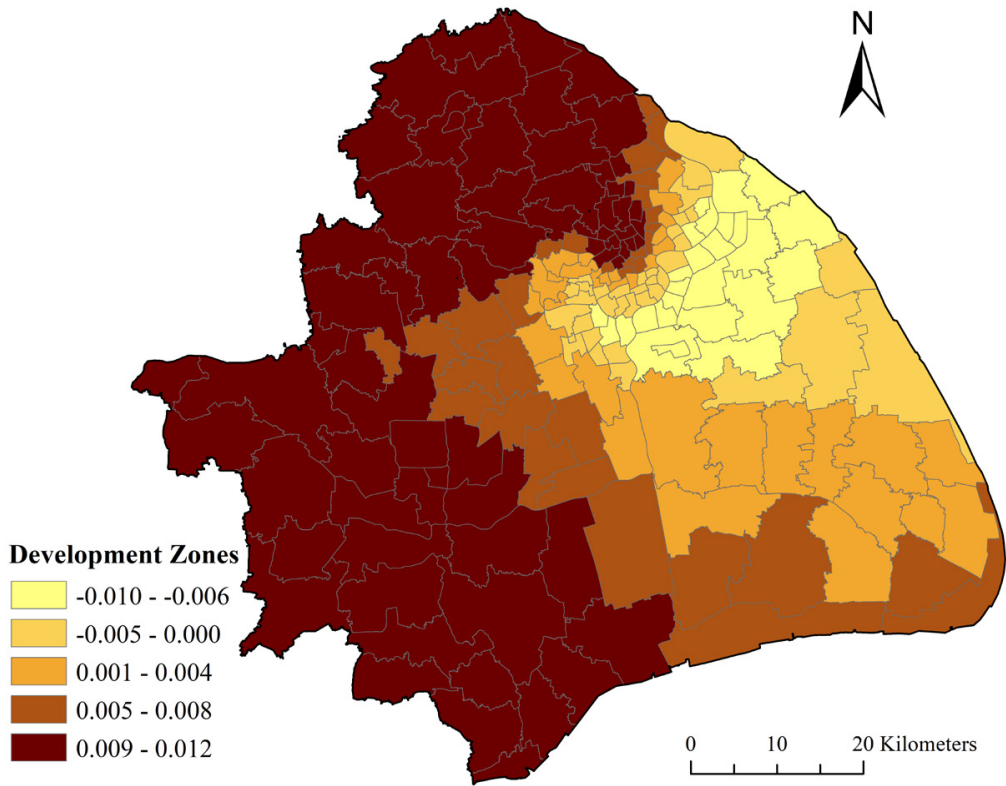

$\mathrm{b}$

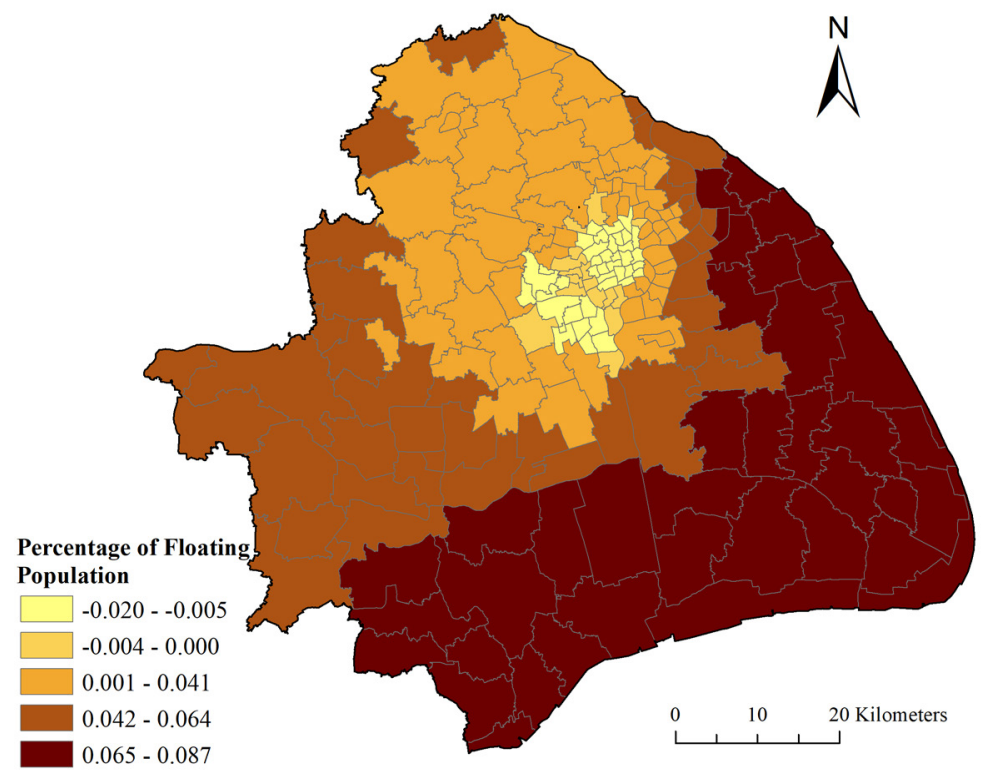

(c)

Figure 6. Estimated coefficient maps of geographically weighted regression, (a) population density (b) development zone (c) percentage of floating population

\section{Conclusion and discussion}

Jobs-housing imbalance is growing in urban China and threatens the sustainability of development and social resilience (Fan et al., 2014; Wang et al., 2011; Xu et al., 2013). Traditional theories find that social and economic inequality, as well as urban structure and amenities, are key factors driving jobs-housing imbalance (Cervero, 2007; Gobillon et al., 2007; Stoll, 2005). However, the Chinese characteristics 
make the jobs-housing imbalance unique in China, such as the administrative system, household registration system, and development zones (Wang \& Chai, 2009; Zhou et al., 2017). This study examines the jobs-housing imbalance in Shanghai from the perspectives of urban structure and inequality, which allow us to quantify the effects of social factors, the administrative system, regional planning policy, and urban amenities.

The spatial mismatch index reveals that in general jobs-housing imbalance in Shanghai mainly happens on the periphery of the expanded central urban area. The ring pattern of jobs-housing imbalance is different from western experience. That is because both job opportunities and urban amenities are highly concentrated in the central urban area of Shanghai. The housing price in the expanded urban area is not extremely high, and this region has good accessibility to the jobs in the central urban area. Thus, a lot of people choose to reside in the expanded urban area. Since the high-skill job opportunities are located in the urban center, and the low-skill jobs such as manufacturing have been decentralized to the urban edge, the highly concentrated population in the expanded urban area leads to a jobs-housing imbalance.

The multilevel and geographical weighted regression models confirm that social factors, administrative system, urban structure, regional planning policy, and urban amenities influence the jobs-housing imbalance in Shanghai. First, the jobs-housing balanced regions are attractive to the floating population because they can easily access job opportunities and save commuting costs. Second, the development zones contribute to the jobs-housing imbalance in Shanghai. There is one exception: Pudong district, where the development zones are jobs-housing balanced compared to the surrounding areas. Thus, zoning policies do not necessarily lead to jobs-housing imbalance because well-developed zones can create a self-contained geographical region with a balanced jobs-housing relationship.

Furthermore, housing prices are found to positively contribute to jobs-housing imbalance. The traditional urban model based on the experience in the Western countries suggest that high housing prices in the urban center would be compensated by reduced commuting cost. However, the model results suggest that a jobs-housing balance cannot help reduce housing prices in Shanghai. Job opportunities are concentrated in the urban center, where the housing prices are extremely high. High housing prices force people to move out of the central urban region to the expanded central urban area and contribute to a jobs-housing imbalance because the job opportunities are still in the central urban area. Regarding the huge population in Shanghai, the high demand of housing contributes to the rise of housing prices in the expanded central urban area. Thus, Shanghai does not simply follow the Western urban model that the regions with good accessibility to job centers would have lower housing prices. Instead, the competition for limited living space in the central urban region, as well as an expanded central urban area, contributes to high housing prices.

On the other hand, factors such as the establishment of the development zones, the development of the transportation system, and high housing prices might be interrelated. For example, development zones have been proven in several studies to contribute to the rise of local housing prices and construction of infrastructure because of the single industry land use for maximizing economic profit (Wei, \& Leung, 2005; Wong \& Tang, 2005). Thus, houses become a scarce resource around development zones, and people have to compete for the residential sites to live closer to job opportunities.

Even though limitations still exist in this study. We employed the subdistrict-level data for analysis, which is the minimum unit available. However, Zhou $\&$ Yeh (2020) suggest that the modifiable areal unit problem (MAUP) exists while estimating jobs-housing balance, which highlights the importance of choosing a proper analyzing unit. In this study, we examine the jobs-housing imbalance in Shanghai at the subdistrict level. Most of the subdistricts are larger than the turning point suggested in Zhou and Yeh's paper (2020) $(2 \mathrm{~km})$, and the impacts of MAUP on the results could be minimized. Even though 
further study should pay attention to MAUP problems and select the proper analytical unit. Furthermore, our datasets are not updated while the population data is from the 2010 population census and employment data from the economic census in 2013. The recent datasets on population and employment are going to be released which could help improve the understanding of the current jobs-housing imbalance in Shanghai. Finally, this study identifies jobs-housing imbalance through the employment/ population relationship using population and economic census. The other issues, such as non-work population and population mobility, which would influence estimating the number of residences, are not considered. As the open data technique is emerging and used to explore urban and social issues, it is expected to improve our understanding of the jobs-housing imbalance.

Although limitations exist, the findings contribute to the literature by explaining the mechanism of jobs-housing imbalance in China's city model. First, the jobs-housing imbalance is caused by centralized planning because the centralized workplaces raise property values, which forces people to move out of the center due to poor housing affordability. This example of Shanghai provides valid evidence to support the hypothesis by Kain (1992) that poor housing affordability would contribute to jobs-housing imbalance. On the other hand, the poorly developed industrial zones, which are very common in developing countries, increase jobs-housing imbalance by limiting the space for housing. Although these industrial zones contribute to rapid economic growth, the jobs-housing imbalance is a significant urban issue that affects sustainable development and social resilience. The success of the development zones in the Pudong district highlights the importance of housing availability in creating jobs-housing balanced communities in the industrial zones.

Moreover, these findings are potentially valuable for the government to deal with the jobs-housing imbalance in urban China. First, the results of the regression models suggest that the street network in Shanghai has been well developed in the jobs-housing imbalanced regions. The major problem is the limited coverage of the metro system in the outer urban areas where many development zones are located. Given the fact that the transportation system contributes to the development of high-tech zones (Zandiatashbar, Hamidi, \& Foster, 2019), extending the metro system to reach the development zones is necessary for Shanghai. Second, the floating population is likely to be influenced by jobs-housing imbalance, and the government should pay attention to the housing needs of the floating population, such as affordable housing projects and public renting projects. Finally, in light of the uneven development in Shanghai indicated by the results of the GWR model, government policies should be adapted to fit the local context.

\section{Acknowledgement}

The authors would like to acknowledge the funding of the Ford Foundation (129647), the US National Science Foundation (1759746), and the National Natural Science Foundation of China (41701183). 


\section{References}

Aguilera, A. (2005). Growth in commuting distances in French polycentric metropolitan areas: Paris, Lyon and Marseille. Urban Studies, 42(9), 1537-1547.

Anas, A., Arnott, R., \& Small, K. A. (1998). Urban spatial structure. Journal of Economic Literature, 36(3), 1426-1464.

Bae, C. H. C., \& Jun, M. J. (2003). Counterfactual planning: What if there had been no greenbelt in Seoul? Journal of Planning Education and Research, 22(4), 374-383.

Bai, X., Shi, P., \& Liu, Y. (2014). Society: Realizing China's urban dream. Nature News, 509(7499), 158.

Campbell, H. E., Kim, Y., \& Eckerd, A. (2014). Local zoning and environmental justice: An agentbased model analysis. Urban Affairs Review, 50(4), 521-552.

Cartier, C. (2001). 'Zone fever,' the arable land debate, and real estate speculation: China's evolving land use regime and its geographical contradictions. Journal of Contemporary China, 10(28), 445469.

Cervero, R. (1989). Jobs-housing balancing and regional mobility. Journal of the American Planning Association, 55(2), 136-150.

Cervero, R. (2007). Transit-oriented development's ridership bonus: a product of self-selection and public policies. Environment and planning A, 39(9), 2068-2085.

Cervero, R., \& Day, J. (2008). Suburbanization and transit-oriented development in China. Transport Policy, 15(5), 315-323.

Day, J., \& Cervero, R. (2010). Effects of residential relocation on household and commuting expenditures in Shanghai, China. International Journal of Urban and Regional Research, 34(4), 762-788.

Ewing, R., Hamidi, S., Grace, J. B., \& Wei, Y. D. (2016). Does urban sprawl hold down upward mobility? Landscape and Urban Planning, 148, 80-88.

Fan, Y., Allen, R., \& Sun, T. (2014). Spatial mismatch in Beijing, China: Implications of job accessibility for Chinese low-wage workers. Habitat International, 44, 202-210.

Feng, W., Zuo, X., \& Ruan, D. (2002). Rural migrants in shanghai: Living under the shadow of socialism. International Migration Review, 36(2), 520-545.

Fotheringham, A. S., Batty, M., \& Longley, P. A. (1989, December). Diffusion-limited aggregation and the fractal nature of urban growth. Papers of the Regional Science Association, 67(1), 55-69.

Fotheringham, A. S., Brunsdon, C., \& Charlton, M. E. (2002). Geographically weighted regression: The analysis of spatially varying relationships. New York: John Wiley.

Gao, B., Liu, W., \& Dunford, M. (2014). State land policy, land markets and geographies of manufacturing: The case of Beijing, China. Land Use Policy, 36, 1-12.

Giuliano, G. (1991). Is jobs-housing balance a transportation issue? Berkeley, CA: University of California Transportation Center, University of California.

Giuliano, G., \& Small, K. A. (1993). Is the journey to work explained by urban structure? Urban Studies, 30(9), 1485-1500.

Glaeser, E. L., Kahn, M. E., \& Rappapo, J. (2008). Why do the poor live in cities? The role of public transportation. Journal of Urban Economics, 63(1), 1-24.

Gobillon, L., Selod, H., \& Zenou, Y. (2007). The mechanisms of spatial mismatch. Urban Studies, 44(12), 2401-2427.

Gordon, P., \& Richardson, H. (1989). The influence of metropolitan spatial structure on commuting time. Journal of Urban Economics, 26(2), 138-151.

Gordon, P., \& Richardson, H. (1997). Are compact cities a desirable planning goal? Journal of the American Planning Association, 63, 95-106. 
Gu, C., \& Shen, J. (2003). Transformation of urban socio-spatial structure in socialist market economies: The case of Beijing. Habitat International, 27, 107-122.

Han, H., Yang, C., Wang, E., Song, J., \& Zhang, M. (2015). Evolution of jobs-housing spatial relationship in Beijing metropolitan area: A job accessibility perspective. Chinese Geographical Science, 25(3), 375-388.

He, C., Huang, Z., \& Wang, R. (2014). Land use change and economic growth in urban China: A structural equation analysis. Urban Studies, 51(13), 2880-2898.

He, Q., Zeng, C., Xie, P., Tan, S., \& Wu, J. (2019). Comparison of urban growth patterns and changes between three urban agglomerations in China and three metropolises in the USA from 1995 to 2015. Sustainable Cities and Society, 50, 101649.

Horner, M., \& Murray, A. (2003). A multi-objective approach to improving regional jobs-housing balance. Regional Studies, 37(2), 135-146.

Hu, L., Fan, Y., \& Sun, T. (2017). Spatial or socioeconomic inequality? Job accessibility changes for low-and high-education population in Beijing, China. Cities, 66, 23-33.

Huang, H., \& Wei, Y. D. (2016). Spatial inequality of foreign direct investment in China: Institutional change, agglomeration economies, and market access. Applied Geography, 69, 99-111.

Ihlanfeldt, K. R., \& Sjoquist, D. L. (1998). The spatial mismatch hypothesis: A review of recent studies and their implications for welfare reform. Housing Policy Debate, 9(4), 849-892.

Kain, J. F. (1992). The spatial mismatch hypothesis: Three decades later. Housing Policy Debate, 3(2), 371-460.

Kim, C., Sang, S., Chun, Y., \& Lee, W. (2012). Exploring urban commuting imbalance by jobs and gender. Applied Geography, 32, 532-545.

Li, H., Wei, Y. H. D., \& Huang, Z. (2014). Urban land expansion and spatial dynamics in globalizing shanghai. Sustainability, 6(12), 8856-8875.

Li, H., Wei, Y. D., Wu, Y., \& Tian, G. (2019a). Analyzing housing prices in shanghai with open data: Amenity, accessibility and urban structure. Cities, 91, 165-179.

Li, H., Wei, Y. D., \& Wu, Y. (2019b). Analyzing the private rental housing market in Shanghai with open data. Land Use Policy, 85, 271-284.

Li, H., Wei, Y. D., \& Wu, Y. (2019c). Urban amenity, human capital and employment distribution in Shanghai. Habitat International, 91, 102025.

Li, L., Lin, J., Li, X., \& Wu, F. (2014). Redevelopment of urban village in China-A step towards an effective urban policy? A case study of Liede village in Guangzhou. Habitat International, 43, 299-308.

Li, S. M., \& Huang, Y. (2006). Urban housing in China: Market transition, housing mobility and neighborhood change. Housing Studies, 21(5), 613-623.

$\mathrm{Li}, \mathrm{S}$. (2010). Changing residential and employment locations and patterns of commute under hyper growth: The case of Guangzhou, China. Urban Studies, 47(8), 1643-1661.

Li, Z., \& Wu, F. (2006). Socio-spatial differentiation and residential inequalities in Shanghai: A case study of three neighborhoods. Housing Studies, 21(5), 695-717.

Lin, G. C., \& Wang, C. (2009). Technological innovation in China's high-tech sector: Insights from a 2008 survey of the integrated circuit design industry in Shanghai. Eurasian Geography and Economics, 50(4), 402-424.

Liang, Z., \& Ma, Z. (2004). China's floating population: New evidence from the 2000 census. Population and Development Review, 30(3), 467-488.

Liu, Y., Dijst, M., \& Geertman, S. (2014). Residential segregation and well-being inequality between local and migrant elderly in Shanghai. Habitat International, 42, 175-185.

Liu, Y., Fang, F., \& Li, Y. (2014). Key issues of land use in China and implications for policy making. Land Use Policy, 40, 6-12. 
Liu, X., \& Wang, M. (2016). How polycentric is urban China and why? A case study of 318 cities. Landscape and Urban Planning, 151, 10-20.

Lobyaem, S. (2006). The effectiveness of jobs-housing balance as a strategy for reducing traffic congestion: $A$ study of metropolitan Bangkok (Doctoral dissertation Texas A\&M University, College Station, TX).

Loo, B. P., \& Chow, A. S. (2011). Jobs-housing balance in an era of population decentralization: An analytical framework and a case study. Journal of Transport Geography, 19(4), 552-562.

Ma, K. R., \& Banister, D. (2007). Urban spatial change and excess commuting. Environment and Planning A, 39(3), 630-646.

Olds, K., \& Yeung, H. (2004). Pathways to global city formation: A view from the developmental citystate of Singapore. Review of International Political Economy, 11(3), 489-521.

Ong, P. M., \& Miller, D. (2005). Spatial and transportation mismatch in Los Angeles. Journal of Planning Education and Research, 25(1), 43-56.

Pan, H., Shen, Q., \& Zhang, M. (2009). Influence of urban form on travel behavior in four neighborhoods of Shanghai. Urban Studies, 46(2), 275-294.

Peng, Z. R. (1997). The jobs-housing balance and urban commuting. Urban Studies, 34(8), 1215-1235.

Qin, P., \& Wang, L. (2017). Job opportunities, institutions, and the jobs-housing spatial relationship: Case study of Beijing. Transport Policy, 81, 331-339.

Qi, Y., Fan, Y., Sun, T., \& Hu, L. (2018). Decade-long changes in spatial mismatch in Beijing, China: Are disadvantaged populations better or worse off? Environment and Planning A: Economy and Space, 50(4), 848-868.

Saadi, I., Boussauw, K., Teller, J., \& Cools, M. (2016). Trends in regional jobs-housing proximity based on the minimum commute: The case of Belgium. Journal of Transport Geography, 57, 171-183.

SCCTPI - Shanghai Comprehensive City Transportation Planning Institute. (2005). Shanghai Comprehensive Transportation Plan, Shanghai, China (in Chinese). Shanghai: SCCTPI.

Shen, G. (2002). Fractal dimension and fractal growth of urbanized areas. International Journal of Geographical Information Science, 16(5), 419-437.

SSB (Shanghai Statistical Bureau) (2014). Shanghai statistical yearbook. Retrieved from http://www.statssh.gov.cn/tjnj/zgsh/nj2011.html\#

SSB (Shanghai Statistical Bureau) (2019). Shanghai statistical yearbook. Retrieved from http://www.stats. gov.cn/tjsj/ndsj/2019/indexeh.htm

Stoll, M. A. (2005). Job sprawl and the spatial mismatch between blacks and jobs. Washington, DC: Brookings Institution Metropolitan Policy Program.

Stoll, M. A., \& Covington, K. (2012). Explaining racial/ethnic gaps in spatial mismatch in the US: The primacy of racial segregation. Urban Studies, 49(11), 2501-2521.

Sun, B., Ermagun, A., \& Dan, B. (2017). Built environmental impacts on commuting mode choice and distance: Evidence from Shanghai. Transportation Research Part D: Transport and Environment, 52, 441-453.

Sun, W., Zheng, S., Geltner, D. M., \& Wang, R. (2017). The housing market effects of local home purchase restrictions: Evidence from Beijing. The Journal of Real Estate Finance and Economics, 55(3), 288-312.

Suzuki, T., \& Lee, S. (2012). Jobs-housing imbalance, spatial correlation, and excess commuting. Transportation Research Part A: Policy and Practice, 46(2), 322-336.

Tian, G., Wei, Y. D., \& Li, H. (2017). Effects of accessibility and environmental health risk on housing prices: A case of Salt Lake County, Utah. Applied Geography, 89, 12-21.

Wang, D., \& Chai, Y. (2009). The jobs-housing relationship and commuting in Beijing, China: The legacy of Danwei. Journal of Transport Geography, 17(1), 30-38.

Wang, E., Song, J., \& Xu, T. (2011). From "spatial bond" to "spatial mismatch": An assessment of 
changing jobs-housing relationship in Beijing. Habitat International, 35(2), 398-409.

Wang Y. P., \& Murie, A. (1996). The process of commercialisation of urban housing in China. Urban Studies, 33(6), 971-989.

Wen, H., \& Goodman, A. C. (2013). Relationship between urban land price and housing price: Evidence from 21 provincial capitals in China. Habitat International, 40, 9-17.

Wen, H., \& Tao, Y. (2015). Polycentric urban structure and housing price in the transitional China: Evidence from Hangzhou. Habitat International, 46, 138-146.

Wen, H., Xiao, Y., \& Zhang, L. (2017). School district, education quality, and housing price: Evidence from a natural experiment in Hangzhou, China. Cities, 66, 72-80.

Wei, Y. H. D., Bi, X., Wang, M., \& Ning, Y. (2016). Globalization, economic restructuring, and locational trajectories of software firms in shanghai. The Professional Geographer, 68(2), 211-226.

Wei, Y. H. D., \& Leung, C. K. (2005). Development zones, foreign investment, and global city formation in Shanghai. Growth and Change, 36(1), 16-40.

Wong, S. W., \& Tang, B. S. (2005). Challenges to the sustainability of 'development zones': A case study of Guangzhou Development District, China. Cities, 22(4), 303-316.

Wu, F., \& Logan, J. (2016). Do rural migrants 'float' in urban China? Neighboring and neighborhood sentiment in Beijing. Urban Studies, 53(14), 2973-2990.

Xu, Y., Chan, E. H., \& Yung, E. H. (2013). Analysis of the mechanisms contributing to spatial mismatch in transitional Chinese cities. Journal of Urban Planning and Development, 140(2), 04013011.

Yang, J., \& Ferreira, J. (2005). Evaluating measures of jobs-housing proximity. In D. M. Levinson \& K. J. Krizek (Eds.), Access to destinations (pp. 171-192). Amsterdam: Elsevier.

Yang, X., Day, J. E., Langford, B. C., Cherry, C. R., Jones, L. R., Han, S. S., \& Sun, J. (2017). Commute responses to employment decentralization: Anticipated versus actual mode choice behaviors of new town employees in Kunming, China. Transportation Research Part D: Transport and Environment, 52, 454-470.

Ye, C., Chen, M., Chen, R., \& Guo, Z. (2014). Multi-scalar separations: Land use and production of space in Xianlin, a university town in Nanjing, China. Habitat International, 42, $264-272$.

You, Z., Yang, H., \& Fu, M. (2018). Settlement intention characteristics and determinants in floating populations in Chinese border cities. Sustainable Cities and Society, 39, 476-486.

Yuan, F., Wei, Y., Chen, W., \& Jin, Z. (2010). Spatial agglomeration and new firm formation in the information and communication technology industry in Suzhou. Acta Geographica Sinica, 65(2), 153-163.

Yue, W., Fan, P., Wei, Y. H. D., \& Qi, J. (2014). Economic development, urban expansion, and sustainable development in Shanghai. Stochastic Environmental Research and Risk Assessment, 28(4), 783-799.

Zandiatashbar, A., Hamidi, S., \& Foster, N. (2019). High-tech business location, transportation accessibility, and implications for sustainability: Evaluating the differences between high-tech specializations using empirical evidence from US booming regions. Sustainable Cities and Society, 50, 101648.

Zhou, J., Wang, Y., Cao, G., \& Wang, S. (2017). Jobs-housing balance and development zones in China: A case study of Suzhou Industry Park. Urban Geography, 38(3), 363-380.

Zhou, J., Chun, Z., Xiaojian, C., Wei, H., \& Peng, Y. (2014). Has the legacy of Danwei persisted in transformations? The jobs-housing balance and commuting efficiency in Xi'an. Journal of Transport Geography, 40, 64-76.

Zhou, S., Liu, Y., \& Kwan, M. P. (2016). Spatial mismatch in post-reform urban China: A case study of a relocated state-owned enterprise in Guangzhou. Habitat International, 58, 1-11.

Zhou, X., Chen, X., \& Zhang, T. (2016). Impact of megacity jobs-housing spatial mismatch on commuting behaviors: A case study on central districts of Shanghai, China. Sustainability, 8(2), 122. 
Zhou, X., \& Yeh, A. G. (2020). Understanding the modifiable areal unit problem and identifying appropriate spatial unit in jobs-housing balance and employment self-containment using big data. Transportation. https://doi.org/10.1007/s11116-020-10094-z 